\title{
Ethics and Fragmented Knowledge in McEwan's Solar: Implications for Big History
}

\author{
Tatiana de Freitas Massuno ${ }^{1}$ \\ Daniel Barreiros ${ }^{2}$ \\ Pontifical Catholic University of Rio de Janeiro ${ }^{1}$ \\ Federal University of Rio de Janeiro ${ }^{2}$ \\ Correspondence | Tatiana de Freitas Massuno, tatiana.massuno@gmail.com_Daniel Barreiros, daniel.barreiros@ie.ufrj.br \\ Citation I Massuno, Tatiana de Freitas, and Daniel Barreiros. 2020. "Ethics and Fragmented Knowledge in McEwan's Solar: \\ Implications for Big History." Journal of Big History 4 (3): 79-96. \\ DOI I https://doi.org/10.22339.jbh.v4i3.4340
}

K E Y W O R D S

Two cultures

Natural sphere

Cultural sphere

World view

Epistemology

Ethics

Anthropocene

Big History

\begin{abstract}
A B S T R A C T
This essay is a reflection on the consequences and outreach of the "two cultures" (as conceived by C. P. Snow) that resorts to a reading of McEwan's acclaimed novel Solar. Michael Beard, the main character, is a Nobel Laureate who, at a very young age, gained recognition, and who then spent most of his adult years wasting his ingeniousness on futile and personal pursuits. He is unable to understand the ethical and humanitarian implications of his gained knowledge. Even though he ends his career by trying to address the problem of climate change, he does so in a detached manner, as though human and nonhuman lives were not implicated in this Earth phenomenon. At the root of it all lies an assumption that nature and culture belong to distinct ontological spheres. Hence, we aim at investigating how Beard's worldview can be read as a symptom of epistemological assumptions that no longer serve us. This article explores the ethical implications of a rigid disciplinary perspective in a moment of global urgency - the Anthropocene -, and how Big History can help to narrow the gap between different forms of human knowledge. It also makes brief remarks on how Big History should avoid the ethical perils represented by the idea of a "grand unifying theory of the past" by assuming a permanent and coherent critical stance on its methods and concepts.
\end{abstract}

Can science still be morally neutral in times of climate change? How do personal stories and planetary ones intertwine in this new geological epoch called the Anthropocene? How does the entanglement between humans and nonhumans affect personal stories? In The Great Derangement, Amitav Ghosh claims that the novel may seem inappropriate to depict the natural disasters we are soon to experience.
Perhaps the same can be said about conventional thought all across the academic fields (and, especially, in the humanities). Climate change, according to Gosh, seems unfit for a literary genre (the novel) that focuses on the individual, on the probable, and in the insertion of the everyday in narratives. The mark of the modern worldview, which the novel embodies, is the assumption, in literature and in geology, that 
(Ghosh 2016, 22), that it makes no leaps, that it is predictable. Any hint of the uncanny is then relegated to less serious fiction. Serious fiction, the novel, on the other hand, represents the mastery of techniques that help conceal the scaffolding of events. Events should bear the mark of probability, one leading naturally to the other, following probable chains of cause and consequence. It is no wonder then that Amitav Ghosh asks himself whether serious fiction could face the obstacles posed by climate change. Doesn't climate change disrupt our deep-rooted epistemological assumptions? Doesn't it question the existence of a nature out there ready to be tamed? Doesn't it beg the revision of time-space scales? Of background-foreground relationships? Likewise, is not academic thought expected to face the same questions, for the same reasons? Is Big History fit for the job? The climate crisis, Ghosh would go on, is a crisis not only of culture, but also a crisis of the imagination (Ghosh 2016, 9). How could the novel accommodate the discontinuities of climate change? How can we imagine and represent the unthinkable? How can academic knowledge cope with this?

Ian McEwan, following his own personal engagement with Cape Farewell, a think tank that gathers creative minds willing to address the reality of climate change, publishes the novel, Solar. The story of the novel revolves around a physicist, a Nobel Prize winner, Michael Beard, who in the midst of his own personal entanglements - failed marriages, affairs, expeditions, revenge, grants, disease, etc. carries out his research on clean energy. Beard's interest in clean energy is not motivated by the world crisis, though. He is not impressed by climate change or any political or external motive for that matter. In a way, the novel as a whole avoids grappling with the representation of climate change. Climate change is presented as a given, as a background noise that clings to the events that unfold. Even though Beard claims to be unimpressed about climate change, his work relies on this fact: that the planet is getting warmer and every now and again the topic is brought up in conversations. Even if at first Solar may seem to be a textbook example of how serious fiction, as Amitav Ghosh stated, is unfit to deal with the problems presented by climate change, many tensions are brought to the surface throughout the novel.

If the allegorical mode is at play in McEwan's novel, as many critics have noted (Kellish 2013; Tate 2017; Trexler 2015), allegory here should not be reduced to the structure of the synecdoche, a continuous relationship between part and whole. Beard's life is not necessarily the microcosm of the planet. Clear distinctions between contexts and boundaries, ones that would allow for microcosm and macrocosm relationships, become blurry in a novel that seems well aware of the interconnectedness of all. Beard's life may be a microcosm and a macrocosm at the same time, and even more, if carefully scrutinized. It is not difficult to realize then that the structure of the synecdoche is at its breaking point in the novel, showing its cracks and tensions as the world is about to reach its climate tipping points.

This essay aims, this way, at investigating the cracks left wide open as the story unfolds. These cracks and tensions relate to outdated worldviews that do not align with a planet in peril, an unthinkable situation that blurs cherished distinctions.

"[H]e was paralyzed by shame, by the extent of his humiliation" (McEwan 2011, 5). In the very first pages of Solar a description of Michael Beard's state of mind is provided: it is a sense of humiliation that infuses his life with a renewed desire for his wife. Knowing about her betrayal makes her desirable again, makes him, Beard, eager to do whatever it takes to have her back. All of a sudden, Beard longs for Patrice and all his thoughts revolved around her: "These days, desire for Patrice came on him out of nowhere, like an attack of stomach cramp" (McEwan 2011, 5). Note that he is not overtaken by higher feelings of love or admiration for his wife; quite the contrary, his feelings are likened to corporeal reactions; he is a body reacting to stimuli and nothing more.

He is a body desiring another he can no longer possess, and humiliation is the driving force behind it all. If he could have her back, would he overcome this sense of humiliation? Would the cramp cease? Would his body give him a rest? 
Michael Beard, the Nobel Prize winner, is driven by his corporeal urges: food, drink, sex. He is a body craving for more and more, even when he is diagnosed with melanoma, even when the doctor warns him that metastasis is a possibility unless treatment started right away, Beard is resolute in his pursuits, he cannot stop: 'Don't be a denier,' Doctor Parks had said, appearing to refer back to their climate-change chats. 'This won't go away just because you don't want it or are not thinking about it"' (McEwan 2011, 328). Beard is not willing to accept this external imposition. We seem to have reached an impasse here. Beard, the physicist, is driven by material urges but not willing to respond to the call of his own body? What is Beard's relation with the material realm?

The material world represents this uncomplicated space governed by laws that can be easily described, understood, manageable: "The material world simply could not be so complicated. But the domestic world could" (McEwan 2011 29). According to Michael Beard, then, the human and the material realms constitute two different worlds that could not be less akin to each other, separate worlds that are governed either by predictable or unpredictable laws that do not interfere with one another: "All the excitement and unpredictability was in the private life" (McEwan 2011, 19).

There is the human world and its despicable human affairs and there is the clean orderly world of physics. At the root of Beard's thought and his apparent despise for culture and society lies a thought, on the surface, contrary to what drove Western civilization:

In the Western tradition, in fact, most definitions of the human stress the extent to which it is distinguished from nature. This is what is meant, most often, by the notions of "culture," "society," or "civilization." As a result, every time we attempt to "bring humans closer to nature," we are prevented from doing so by the objection that a human is above all, or is also, a cultural being who has to escape from, or in any case be distinguished from, nature (Latour 2017, 14).

At first, Beard's conviction seems to contradict the western attempt to free itself from natural constraints. That is, it seems to contradict modern conceptions that oppose the natural and human worlds. According to this modern view, human consciousness and its ability to elevate itself from nature guaranteed the progress of human history. It sees the natural world as a mere background to human history. To put it another way, it means that mankind's freedom and consequential progress is made possible only by silencing nature: "Freedom has been the most important motif of written accounts of human history of these two hundred and fifty years" (Chakrabarty 2009, 208).

Michael Beard's conviction-that there is a separation between the human and natural worlds-resonates with what Bruno Latour in We Have Never Been Modern (1993) calls the Great Divide. Modernity's rupture with the pre-modern world entailed conceiving the world through a clear separation between natural and human realms, that is, between nature and society and, as consequence, between subject and object. The natural world is seen as stable and constantly equal to itself, as background. It is not allowed consciousness or intention. It may only bear witness to human actions, intentions, progress. The natural world does not interfere with human actions and intentions and remains always the same. Let's listen to Beard again: unpredictability is relegated to the human realm, only. The material world, the world of physics, is the orderly world of predictability. If at first Beard seems to elevate the material realm, he does so by means of restating the modern epistemological assumptions. The material world is elevated due to its silence, its lack of agency and volition, but what about his body?

If Michael Beard's claims initially seem to downplay human affairs, they do so by means of undermining the material realm as well. The world of physics, the background, is the world of laws, of physical states, the world of facts, then. Its laws, therefore, cannot be applied to the human realm: "Beard said that the principle had no application to the moral sphere. On the contrary, quantum mechanics was a superb predictor of the statistical probability of physical 
states" (McEwan 2011, 106). From the beginning of the novel Beard is quite clear about his line of reasoning: the need to separate human affairs from the world of physics, the clear-cut division between facts and values. The philosophers of science should not tell him otherwise! Michael Beard, the Nobel Prize winner, is an almost hyperbolic depiction of a modern scientist. His claims, his utterances, restate time and again his alignment with the facts, as opposed to any value these facts may embody. As a scientist, facts are just facts for him and nothing more. The laws of physics have no say in the moral sphere and vice versa.

This simplistic view, however, does not fully grasp how multi-faceted McEwan's novel is. Solar, alongside Oryx and Crake by Margaret Atwood, is one of the first novels written by literary giants to grapple with climate change. Climate change, nonetheless, may not seem to be a main concern in the novels at first glance: while in Atwood's novel, according to Adam Trexler, climate change is nothing more than a footnote; in McEwan's novel, science is the least of Beard's concern. What to expect, then, from Beard, whose ingeniousness was supposed to save the dying planet?

Throughout the novel, science remains the least of Beard's concerns: the novel's comic force comes from Beard's self-centered preoccupation with his next meal and the repercussions of his last, foggily fighting the effects of drinks he didn't mean to take, pursuing women and mitigating the effects of his affairs, keeping sinecures and securing patents, and attracting undue credit to consolidate his reputation, even if the fate of the world, apparently hangs in balance. And this is much the point of the novel: Beard's immediate desires continually displace action that should prevent climate change (Trexler 2015 47).

Interestingly, in spite of Beard's continual claims about physics' awkward superiority, superior precisely because it is free from human taint, ${ }^{1}$ throughout the novel, science, or even physics, becomes a mere background, whereas "human affairs" come to the forefront. His research occupies little of his time; it becomes almost irrelevant after the Nobel Prize winner discovers he is a cuckold, and saving the planet from the sixth mass extinction seems less important than regaining his wife's love and affection. Notice the parallelism, which is one of many in the novel: the fifth marriage and the impending sixth mass extinction, both of which could have been averted by him-Michael Beard: the husband and the Nobel Prize winner. When posed with the impossible choice of which should be salvaged, Beard, without a moment of hesitation, gravitates toward human affairs: "At no point did he remember that the planet was in peril" (McEwan 2011, 51). Beard did not love Patrice, though; he was overtaken by a sudden craving for her. Shame and humiliation were behind his new impulses. Adam Trexler would say Beard was a victim of "evolutionary urges," "the result of evolutionary instincts operating just beyond his awareness" (Trexler 2015, 48). Andrew Tate would add that "regressive forces" prevented him from focusing his attention on saving the Earth:

These confrontations display McEwan's fascination with scientific materialism and a certain clumsily allegorical mode: the liberal, progressive conscience finds itself in continual opposition to antagonistic, regressive forces that are not just wrong-headed but literally pathological. Michael Beard belongs to this trope of masculinity in crisis but instead of finding some vicious doppelgänger, Beard's own adversary is himself: he is clever enough to have been awarded a Nobel Prize as a young man but not smart enough to keep himself in good physical or moral health (Tate 2017,7 ).

Humiliation, the novel says. Curiously, humiliation is also the term Timothy Morton chooses to describe how hyperobjects, global warming being one, affect our perception of the human. In his words, "Hyperobjects seem to continue what Sigmund Freud considered the great humiliation of the human following Copernicus and Darwin" (Morton 2013, 16). The list of humiliators goes on to include Freud, Marx, Derrida, Heidegger, Nietzsche and his lineage, thinkers 
that displaced the human from the center of psychic activity, the center of meaning-making, or displaced human social life; hyperobjects, following this line of thought, seem to push this displacement to a new limit, one in which, according to Morton, we are forced to "realize the truth of the word humiliation itself, which means being brought low, being brought down to earth" (Morton 2013, 17). These objects, massively distributed in space and time, impose the painful realization that "we are always inside an $o b$ ject" (Morton 2013, 17). We cannot escape global warming. It is in our bodies, in our simple conversations about the weather; it reaches remote territories and big cities; it affects the Earth in its entirety. Global warming viciously attaches itself to our human affairs, as the hyperobject it is, showing us time and again that there is no away. We are humiliated, circumscribed by circumstances we cannot escape, limited by the unintended consequences of our own actions. Michael Beard is also humiliated-by the unintended consequences of his actions? The parallelism, nevertheless, between his decaying marriage and the planet does not mean Beard responded the same way to both threats. Climate change "comprised the background to the news," but was not his major concern:

And he was unimpressed by some of the wild commentary that suggested the world was in 'peril', that humankind was drifting towards calamity, when coastal cities would disappear under the waves, crops fail, and hundreds of millions of refugees surge from one country, one continent, to another, driven by drought, floods, famine, tempests, unceasing wars for diminishing resources. There was an Old Testament ring to the forewarnings, an air of plague-of-boils and deluge-of-frogs, that suggested a deep and constant inclination, enacted over the centuries, to believe that one was always living at the end of days, that one's own demise was urgently bound up with the end of the world, and therefore made more sense, or was just a little less irrelevant. The end of the world was never pitched in the present, where it could be seen for the fantasy it was, but just around the corner, and when it did not hap- pen, a new issue, a new date would soon emerge (McEwan 2011 20-21).

For Beard, the real emergency was his marriage. The end of the world belonged to a future he was not even able to anticipate. Would he even see this future? It seems as though there were different types of humiliation, one that could be ignored, dismissed, overlooked, and another that demanded action. Earth's call, in Beard's view, could be silenced. But why is that?

Once again Beard's distinction between humans and nonhumans resonates with our modern assumptions. The silencing of the nonhumans, their removal from our moral sphere, results in being desensitized to their call. Nature's call is, quite the contrary, too loud. Kant perceived it. Nature's potency could easily belittle us humans by disclosing our impotence when confronted with nature's powers. We had to learn to be insensitive to nature's call: "To become moral in the modern way, it is necessary to take shelter from the world and to observe nature as a spectacle, all the more attractive for its fearfulness" (Hache and Latour 2010, 317). Without this separation, without the glass that separates humans and nonhumans and safeguards our humanity, the sense of the sublime evaporates and our humanity is faced with its constitutional weakness:

Nature's appeal from inside us amounts to little: we need not "bow down" to it, and "this saves humanity in our own person from humiliation." Note the seesaw effect: the sense of humanity within rises as the appeal of nature is lowered (this order of precedence will be reversed by Lovelock) (Hache and Latour 2010, 317).

There is, therefore, a need to lower nature's appeal in order to save our humanity from humiliation. Curiously, humiliation plays a role in Kant's thought as well. Relegating the nonhumans to the world of facts saves humanity from humiliation. There needs to be a glass of separation, the world should be viewed as a spectacle; otherwise, what might happen?

Otherwise, we would feel humiliated, Timothy Morton would say. Isn't that what the reality of global warming makes us face? Suddenly, nature, 
the background to human actions, is no longer immutable: "Now what happens when global warming enters the scene? The background ceases to be a background, because we have started to observe it" (Morton 2013, 102). The concepts of background and foreground reach their breaking points, as we are no longer able to tell one from the other: "In an age of global warming, there is no background, and thus there is no foreground" (Morton 2013, 99). Are we part of the spectacle now?

In short, the relationship of human beings to the natural world we inhabit has been upended. None of this could have been foreseen a century ago, or even three decades ago. Yet now we must face up to the fact that this situation, an irreversible and dangerous shift in the Earth's trajectory, is our future and the ideas that we have inherited from the era before the break must all be open to question. Among many that I will later challenge, one is worth mentioning here. It appears that the wanton use of our freedom and technological power have led us to the brink of ruin. The very cultivation of our powers has left us exposed to a nature that refuses to be tamed and is increasingly unsympathetic to our interests (Hamilton 2017, 35).

Michael Beard, the physicist, is unimpressed by climate change, though. Being impressed by it would definitely mean, as Clive Hamilton mentioned, revising our concepts and beliefs, accepting that former ideas about nature, science, humanities, ethics, facts and values no longer fit our new geological age. Nature cannot be observed from a distance anymore since the glass that allegedly separated humans and nonhumans cracked. Beard clings to outdated modes of thinking as though nothing had changed, as though the reality of global warming did not challenge our views on science, as though facts and values could still be viewed as separate entities. When faced with too many humiliations, he attends to the one that does not challenge his scientific views. That is, the novel as a whole explores parallelisms: the comparison between his marriage and the six mass extinctions, between his rela- tionship to his body and the planet, between McEwan's personal experience and episodes in the novel, ${ }^{2}$ situations that don't necessarily mirror one another, but that, when paired, expose clear contradictions. If there is a mirroring effect between his marriage and the planet in peril, why is the planet's call silenced? Focusing his attention on Patrice's moves, trying to regain her love would still mean being safe within the boundaries of human affairs. Human affairs might be unpredictable, as Beard thinks; nonetheless, there was still a line, a boundary, a limit. Responding to the planet's call, on the other hand, signified crossing a line between humans and nonhumans, between facts and values, and acknowledging that "Scientists would have to accept their responsibilities, in Donna Haraway's sense: they would have to become capable of responding, would have to acknowledge that they have 'responseability." (Latour 2017, 29). Beard did not want to take that chance, however; he was a scientist who would stick to the facts, "He was aggressively apolitical" (McEwan 2011, 53). But what is to be done when the facts are such that they are almost prescriptive, when their call to responsibility is just too much to be ignored?

We owe to the astute Republican strategist Frank Luntz, a psychosociologist and unrivalled rhetorician, the celebrated inventor of the expression "climate change" in the place of "global warming," the best formulation of this profound philosophy: the description of the facts is so dangerously close to the prescription of a policy that, to put a stop to the challenges addressed to the industrial way of life, one has to cast doubt on the facts themselves (Latour 2017, 34).

When facts and values are so intertwined, as in the case with global warming, that accepting the facts signifies a change in behavior, sacrificing beliefs and systems, the only possible solution is to deny the facts, to minimize their relevance, and to demand more proof. The facts are not enough, one could say; we need more evidence, others may retort. "Don't be a denier," that is Doctor Parks' response. Global warming won't go 
away, the melanoma won't go away, even if we don't think about it.

But we will not rescue the earth from our own depredations until we understand ourselves a little more, even if we accept that we can never really change our natures. All boot rooms need good systems so that flawed creatures can use them well. Good science will serve us well, but only good rules will save the boot room. Leave nothing to idealism or outrage, or even good art. (We know in our hearts that the very best art is entirely and splendidly useless) (McEwan 2005).

In a way, Michael Beard is a sorrowful, idealtype for the anomie-stricken modern man, adrift in the vastness of complexity. Unable to grasp the all-relatedness of nature, which dilutes the cultural, the biological, and the physical realms in a continuum, he goes astray under the stars, with lighthouses and seagulls in sight. He cannot find a path for reconnecting his life as an individual to the life of the cosmos because he is saturated by an ideological conviction-in spite of all the evidence-that his life and the life of the cosmos are ontologically and epistemologically unrelated and, therefore, should be encased in different vacuum chambers.

That is an old epistemological, existential and political stance, but, all in all, recentness and oldness are just a matter of scale. In the early nineteenth century, a man like Alexander von Humboldt-a scientist, like Beard-was bold enough to see the universe in a big picture (in the biggest picture he could get), and, actually, he was in good company at the time. Humboldt's Kosmos (1845-1862) was one among many attempts to grasp the lines of unification between multiple scales of existence in space-time (a concept coined latter, of course) (Christian 2018b, 5).

In considering the study of physical phenomena, not merely in its bearings on the material wants of life, but in its general influence on the intellectual advancement of mankind, we find its noblest and most important result to be a knowledge of the chain of connection, by which all natural forces are linked together, and made mutually dependent upon each oth- er; and it is the perception of these relations that exalts our views and ennobles our enjoyments (Humboldt 1864, 1).

For sure, Humboldt's willingness to see the integrative fluxes between extraterrestrial cosmic phenomena and planetary biological and physical ones goes as far as the Zeitgeist of his age admitted, and, on this matter, he was far from being a New Age guru. In spite of this, a "search for conceptual unification" motivated much of the efforts of other nineteenth century thinkers like Comte, Marx, and even the controversial Spencer, favoring macro-narratives that allowed (some) convergence between natural history and-let us use this term-human history. Even Leopold von Ranke, the Teutonic godhead of all positivist historians, could not avoid the claim for unification and warned against the perils of the emphasis on short-term histories (Christian 2019, 5). Was not Maxwell showing that electricity and magnetism were slightly different expressions of the same force, even if he had to rely on the supposed existence of a phlogiston-like stuff, spread all around the cosmos, called ether? (Hawking 2015, 32-33). Good science proceeds with caution and parsimony, and we should not bother too much about an ad hoc hypothesis made for bridging gaps because, sooner or later, it will be supplanted by the "real" thing. Patience requires a refined perspective about time, and both are lacking in Beard's portfolio, among other things.

Maybe we could say that a "consilience" stance, as would be defended by E. O. Wilson (2018, 2931 ), was taking its primeval steps in the 1800 , and that we are insisting on this idea just to highlight the amount of anachronism brought forth by the disturbed personality of a twenty-first century climate scientist-and compulsive denier-such as McEwan's Michael Beard. Perhaps this could be good if we stopped blaming the entire Enlightenment movement for our mainstream shortsightedness and started to consider that, duration -wise, the fragmentation of academic knowledge is much younger than that, and the reaction against that fragmentation is probably one of the most pressing matters of our time.

Most Enlightenment thinkers were convinced that a better and more coherent understanding 
of reality would advance the progress of humanity as a whole. It is possible to identify two overlapping colours or qualities to the Enlightenment's unifying project. [...] It assembles diverse types of knowledge, like so many coloured tiles or pixels, into coherent accounts of how things came to be. Such narratives can be found at the heart of most religious traditions. The second approach can also yield large unifying narratives, but its primary emphasis is on conceptual unity, on the search for networks of ideas that are locked together tightly enough to provide a foundation for most of knowledge (Christian 2019, 5).

The Age of Enlightenment had room for consilience efforts; actually, some were made, but Beard would not be authorized to reclaim this heritage even if he declared such intentions. What Michael Beard inherited from his intellectual ancestors was not this desire for "conceptual unification;" instead, he received the keys and the deed to a Victorian manor, with many compartments, rooms and doors, the vast majority of them closed from inside, with plenty of skeletons in all closets.

The foundations of this house were laid in the last decades of the nineteenth century, and by the early twentieth century, the edifice was quite complete. It was built with the most modern science and techniques, but over ancient burial grounds, where all the past martyrs of Anthropocentrism were put to rest. They should be remembered for their contribution to the human understanding of the universe and our place in it. Yet, as Comte once said, "the living are always, and progressively, governed by the dead" (1978, 151), and even if the agreed meaning of this phrase can be different from the one we are suggesting here, overall, the idea fits well. With German universities as a model for a wide reformation of academic environments around the world, "specialization and professionalization [broke] scholarship into ever-smaller compartments." Not only were the natural sciences and the humanities split apart, but inside each one of these major compartments, a myriad of smaller ones emerged, encapsulated and disconnected from each other. Then "the idea of a single world of knowledge, whether united by religious cosmologies ... or by scientific scholarship ... was abandoned," (Christian 2018b, 5), and in the wake of this process, "discipline based research flourished, a bit like potted plants because it was confined," and "where thought threatened to sprawl unmanageably, the disciplines pruned overreaching branches and root systems, creating the intellectual equivalent of a bonsai garden" (Christian 2019, 6). "In order to accommodate the rising flood of information, scientific disciplines were dividing into specialties at nearbacterial rate" (Wilson 2018, 30).

During this process the humanities quickly emerged as a field of study, carving its name on the pantheon of human knowledge with bones dug up from newly turned earth. In the core of this freshly arisen academic bubble, redivivus, anthropocentrism reigned. In tandem with the idea that the "human realm" and the knowledge about it should belong to a discrete epistemological and ontological sphere, unrelated to anything "natural," anthropocentrism would end up flirting with dystopia, in spite of its good intentions (of which hell is full, some people say). Secular conservatives and liberals alike were fast to condemn the "heresies" of Darwin in the late nineteenth century in an almost hygienist struggle to clean up the miasmatic vapors blown over the "high culture" and the "civilization" by the mere image of a monkey-man. They were followed by the Boasians and other tribes of cultural anthropologists, diffusionists and relativists, in their relentless crusade to save human dignity from being bestialized by the impurities and the brutishness that sprout from the "natural world" (Foley 2003, 17-19). Holistic thinkers should have known better by that time: consilience became a lost cause in the beginning of the twentieth century, and academic institutionalization would not be of any help in this situation.

It was not just a sublime matter of epistemology that drove Michael Beard to a nihilistic, careless posture toward climate change. Academic work, as a job, became dictated by bureaucratic whims and a sort of industrial division of labor, with expected products to be sold in a competitive market. "Western intellectual life is ruled by 
hard-core specialists ... Starting with the deliberations of department-level search committees, then recommendations to the dean of the faculty ... the pivotal question asked was, 'is the candidate the best in the world in his research specialty?" (Wilson 2018,: 31). For a long time, there would be no place for people eager to sprint over no-man's land, over the dead zones at the borders of two or many of the so-called "disciplines". The situation would become even harder for transdisciplinarity advocates (spiritual heirs of the polymaths of the past) after the horrors imposed by Nazi-fascism and its reliance on nefarious pieces of pseudoscience such as Social Darwinism. "These undermined the credibility of the Enlightenment project, and encouraged a turning away from unifying schema towards less ambitious scholarly agendas," especially after the Second World War (Christian 2019, 8).

In the aftermath, not even a glimpse of naturalistic epistemology could be traced in the core of the humanities without raising disgust and accusations. Christian says that the chasm between the two cultures became even wider in the Anglophone world, where the word "science" is exclusively related to the natural sciences (Christian 2018 b , 6). We do not believe it made any big difference. To the speakers of the "sweet language," the "last flower of Latium," ciência, in general, means a "knowledge that is acquired through reading and meditation, instruction, erudition, wisdom" (Ferreira 1975, 324). In spite of this all-encompassing reference, the two cultures, neglecting dictionary definitions, became deepseated in the academic environment in the Lusophone world, in tune with its English-speaking counterparts.

Why does Michael Beard believe in a human domain tainted by chaos and unpredictability, and in a stereotyped physical domain full of regularities? Even the most reluctant student of astrophysics comes to a time when she or he must face the fact that the entire cosmos is created by quantum fluctuation events, and that quantum gravity is certainly the key to unlocking the secrets for the unification of general relativity and quantum mechanics (Susskind 2006, loc. 10631074). Quantum probabilities and wave functions would not confer the exactness expected by a man so full of certainties as Michael Beard; so, we have to presume that he is either a cynic with a full-time job-and not of the Athenian type-, or a very bad physicist, with a Nobel medal in a case.

It is known that laureates tend to display patterns of behavior and ideas considered obnoxious, extravagant, or arrogant; Linus Pauling (a double laureate, by the way) claimed he found the cure for cancer in high doses of vitamin $\mathrm{C}$ and felt that his unmatched excellence would permit him to reach that conclusion with just a few unstandardized trials. Was Michael Beard showing signs of "nobelitis", whose "most common symptom . . . is megalomania" and a personal belief that the affected person has "super-human powers," and that they will "go on and do even bigger and better things" (Diamandis 2013, 1573)? Were the fixation on his cheating wife and the disregard of his medical condition both evidence of aberrant behavior produced by standing on the top of an ivory tower? Was Beard deluded about his power of doing "bigger and better things," not for the world, but for his ego? Is denialism just a nastier form of egolatry? In a way, we could say so, but we are not in favor of appealing to a malady in order to make Beard's behavior make sense. Beard's epistemological disjunction is a collective, societal, civilizational matter. If it were a disease, it would be a widespread endemic one. Prophylactic measures would be a colossal endeavor in order to flip upside down an entire set of mentalities crystallized for centuries and deeply reinforced by academic institutionalization in the late nineteenth century.

Deniers come in many colors and shapes, and their agendas may vary. Nonetheless, they are all believers in the unconstrained power of human action, whether justified by a simplified understanding of free will, or sanctioned by the allegiance to big moralizing gods. In any case, a denialist stance imbues the agent with a strong sense of individual power and invulnerability; at the same time, it establishes an antagonistic relationship with anything considered "external." Narratives about the "taming" of nature, considered a savage and fearful enemy or, at least, a dangerous landscape, reinforce the denialist posture. Tales 
like that-the human epic against nature-are probably as old as mankind, but they were much bolstered by the ideological framework of the industrial society and, unfortunately, by most of the Enlightenment movement.

With the compartmentalization of human studies in the late nineteenth century, the myth of human supremacy was strengthened even further.

In spite of all the efforts in the field of sociology, and the slight exception represented by Marxism, ${ }^{3}$ the apparent lack of genuine verifiable statements, the imperviousness to quantitative methods, and the inadequacy of law-like structures of explanation reinforced the notion that human studies have "freedom" and "indetermination" not only as its subject, but as an epistemological assumption. By that time "Historical scholarship seemed to have splintered into multiple, incommensurable, stories about the past, each representing a particular perspective, and none confident about its claims on historical truth" (Christian 2018b, 8), while economics, trying to escape from "subjectivism's gravitational pull," lost its "humanity" and became a sort of behavioral engineering with the Neoclassical school.

So, Michael Beard is a late heir to this historical epistemological split in academic culture, but not of a regular kind.

The non-scientists have a rooted impression that the scientists are shallowly optimistic, unaware of man's condition. On the other hand, the scientists believe that the literary intellectuals are totally lacking in foresight, peculiarly unconcerned with their brother men, in a deep sense anti-intellectual, anxious to restrict both art and thought to the existential moment (Snow 1961, 5-6).

In this pool of mutual prejudice, Beard contradicts both expectations. Let's imagine for a moment that C. P. Snow's aforementioned image is something factual in its terms, and not just an expression of biased visions reinforced by the academic chasm between the humanities and the natural sciences. While literary intellectuals would believe that Beard, as scientist, should be naïve in relation to "man's condition," he proves to be well aware of the supposedly tricky, unpredictable aspects of personal and social life (a stereotypical notion, of course). On the other hand, his fellow scientists would believe that he is "concerned with their brother men," but his obsession with a failed marriage in spite of the incoming climatic disaster would prove the opposite.

Solar may not be a full-fledged cautionary tale, but perhaps Beard's pre-cataclysmic folly can teach us a thing or two about the dilemmas faced by academic knowledge in the Anthropocene. Michael Beard's views are a construct formed by the worst of two worlds. His understanding of human affairs is not just a cliché; it is also based upon an impoverished approach to the epistemology of the humanities, and his views about "nature" and the knowledge about it are also incomprehensibly inaccurate. Beard somehow sees the universe as a static background, a scenario through which definable entities formed by matter and energy, with intrinsic properties, move in deterministic ways. It is as though Beard is unwilling to let the Newtonian atomism die.

According to the atomistic view, particles simply have the properties they have, regardless of context ... [and] there is no reason for a world composed of atoms with fixed properties to be complex. . . The common view, which we have inherited from Newtonian science, is that we live in a universe composed from a great many identical parts. The partsthe elementary particles-are each very simple, and each is identical to every other of its kind (Smolin 1997, 218, 220).

Beard seems to be unprepared for a more challenging approach to physics and cosmology, one that takes into consideration not circumscribed entities, but relationship networks.

If there is no absolute space then the position of a particle cannot even be spoken of without bringing in its relationship with the rest of nature. ... Atomism compels us to postulate that the world is essentially simple, while relationalism pulls the opposite way, towards a vision 
of the world as a complex system (Smolin 1997, 218).

He also seems incapable of understanding that the humanities (history, in particular) in a largest scale approach must also be fully relational, like non-atomist physics: In order to have "a history of the largest possible scope that can be affirmed for all human beings-an enabling assumption is required, namely, the assumption that some sort of ultimate coherence underlies humanity in general" (Megill 2015, 313).

Readers of this journal are probably aware of Big History's objectives. In Christian's words,

Big history recognizes no disciplinary barriers to historical knowledge. . . . It tries to link the findings of specialist scholarship into a larger unifying vision. . . . With these qualifications, Big History aims at a comprehensive understanding of history, the intellectual equivalent of a world map of the past. Like a world map, the big history story can help us see not just the major nations and oceans of the past, but also the links and synergies that connect different scholarly continents, regions and islands into a single knowledge world (Christian 2018b, 13).

The recent "historical turn" in the natural sciences did much for creating bridges to the humanities so that transversal efforts could be made having the idea of consilience as a north. Big historians are not the only ones to have the search for consilience as a guideline; the call to rescue this old objective-attaining forms of knowledge as unified as possible - was made initially by the British polymath William Whewell in the early nineteenth century (Snyder 2019), and was echoed by the biologist E. O. Wilson in the late twentieth century (Wilson 1998). Researchers not involved in the Big History movement-in the sense given by Katerberg (2018) - have also embraced this objective, albeit sometimes with more modest ambitions and relying a little more on disciplinary safe grounds (Haldon et al. 2018).

Big History is not only a transdisciplinary project; it is also a symptom of the challenges we are facing. In fact, much has been done in terms of accumulation of information and of "vertical" knowledge (ultra-specialized) since the late nineteenth century. Nevertheless, the most important questions that affect us-the planet, all life, humans included-in this first half of the twentiethfirst century are on such a gargantuan scale (spatial and temporal) that it makes disciplinary knowledge insufficient.

We will need the broad scale of big history to see the Anthropocene clearly, because it is not just a turning point in modern world history, but a significant threshold within human history as a whole, and even in the history of planet [E]arth. Most contemporary historical scholarship studies the last 500 years. The danger of this foreshortened perspective is that it can normalize recent history, making the technologically and economically dynamic societies of recent centuries seem typical of human history in general (Christian 2018b, 15, 18).

What Big History brings to the table is the idea that "the very notion of detail is relative." So "what is central at one scale may be detail at another and may vanish entirely at the very largest scales," and, therefore, "larger objects [must] come into view, objects so large that they cannot be seen whole from close up" (Christian 1991, 226). This is, give or take, the same general principle we can adopt to understand the nature of spacetime in a superstring M-theory approach.

If you look at a hair under a magnifying glass, you can see it has thickness, but to the naked eye it just appears like a line with length but no other dimension. Spacetime may be similar: on human, atomic, or even nuclear physics length scales, it may appear four dimensional and nearly flat. On the other hand, if we probe to very short distances using extremely high energy particles, we should see that spacetime was ten- or eleven-dimensional (Hawking 2001, 173).

Big History can be understood as a collective response to the defiance posed by the contemporary relationship between humans and nonhumans.

The Anthropocene is radically de-centring humans and has led to the placing of human 
activity in deep co-evolutionary time. ... It has afforded an opportunity to conceptualize history in a completely new and unexpected manner, to give up the traditional view of "human exceptionalism" and to integrate the environment and other forms of life into history writing, but no longer as passive objects or external decorations, but as active agents in their own rights (Tamm 2018, 6-7).

That is the kind of challenge accepted by a consilience-driven initiative like Big History. It seeks to raise public awareness about historical processes on scales so large that they are not visible from a regular, individual, common sense perspective. To do so, Big History must investigate the feedback mechanisms between human agency in the short term; the long-term institutional frameworks (rules and expectations that emerge in a given society in order to regulate social interactions); and processes occurring at cosmological, geological and evolutionary scales. Therefore, Big History embraces the idea of a continuum between humans, the biosphere, and the cosmos, a continuum that produces different types of phenomena in different spatial and temporal frames. Most of these phenomena, in spite of changes in cosmological and/or evolutionary rhythm and scale, affect the daily lives of many specieshumans included.

Let us, for a moment, assume the perspective of modernization theorists like W. W. Rostow (1971). We should believe that economic and demographic growth is some kind of "propensity" in human societies, and that the "failure" of attaining high levels of income, production and population are due to endogenous handicaps. Rostow restricted his analysis to processes and events since the nineteenth century, so he did not have any longue durée expectations about the problem of growth; but maybe we could dare a little and consider that since the agricultural revolution, "growth" is something on the horizon. We should have ten thousand years of this epic of progress and the taming of the elements. In one way or another, this is just a glimpse of 300,000 years of the presence of $H$. sapiens on this planet, and we can easily accept that for 290,000 years (or even more), there had been no economic or demo- graphic growth capable of calling the attention of an economist.

Human history consists of about 250,00o years of relative stasis followed by a mere 10,000 years of growth, most of which has been concentrated into the last few hundred years. ... To the extent that population growth can serve as a surrogate for growth in average levels of productivity, we must conclude that growth, far from being the normal condition of humanity, is an aberration (Christian 1991, 230).

This is the "play of scales" that Big History, based on a consilience stance, employs in order to raise public awareness about decisive challenges that we, as members of societies, as part of the biosphere and of the cosmos, are facing right now. Human-induced climate change is the result of the combination between the accumulation ethos (with free-market, planning or planification, whatever), the industrial revolution, geopolitical strife, the fossil economy, human supremacy as cultural standpoint, and the unconscious social ethology that gives rise to conflict, status-seeking and agonistic behavior. Humaninduced climate change is literally a "time bomb," not because it is about to explodeunfortunately, it already did-but because the vectors of causality run in different temporal scales, and converge to a single point in timenow.

Modernization theorists and most of the economists, historians, political scientists, sociologist, and geographers-you name it - chose to remain unaware and entrenched in their disciplinary strongholds; the incursions of some of them into sustainability, environmental studies and holistic approaches are not always convincing, because a deep change in epistemological, ethical and existential stance hardly results from it. Even flesh and blood climate scientists fall prey to the negative side of the emotional detachment toward their research objects and to the "objective" approach to those objects (as "serious" science demands). So did the fictional Michael Beard, who, confronted with the consequences of the Anthropocene, chose 1) to make a sinecure of his academic job, a source of personal prestige; 2) to 
embark upon the soothing fantasy of an ordered and predictable universe as a counterpoint to his messy personal life; and 3) to devote the remainder of his years to his love affairs and bodily pursuits. We are not resorting to a cheap moralism here; Beard was free to pick his path according to the given circumstances. Rather, the point is that in Beard's story climate change remains in the background. It is there; what a pity; let's move on with our lives just the way we always did. Beard's life is not transformed by knowledge. He simply chooses not to care.

This brings us to the last subject of this essay. How transformative should ciência be? We are not referring to science, isolated, self-absorbed, but to the entire Portuguese above-mentioned definition, in full: human knowledge, from many sources, combined. What is it for? What should it be for? If Big History can work as a hub, attracting researchers from many fields, guiding them toward transdisciplinarity, we could have it not only as a source of ideas, information and achievable solutions to concrete problems, but also as a beacon, attracting all agents of knowledge-and their interlocutors-to a commitment with an "integral ethical responsibility" once and for all. According to Christian,

Big history is an origin story for the Anthropocene Epoch. ... Big history builds on the intellectual achievements of modern science, but it is also the product of an increasingly globalized world (Christian 2018b, 17).

Origin stories attempt to hold together and pass on all that is known in a given community about how our world came to be as it is.... As far as we know, origin stories can be found at the core of all forms of education (Christian 2018b, 16).

Christian resorts to the image of ethnonarratives as an analogue to Big History for a purpose. "Ethno-narratives are a special genre of narratives that involve a transformation of the self and the community, in a mutual interrelationship" (Bhattacharjee and Dev 2006, 5).

Narrative identity is also based on a responsibility towards the other. The self of the narra- tor is enacted through this responsibility of constructing spaces for dialogue and solidarity in situations of conflict. Narrative, through a programme of shared meanings and memories reconstructs cultural and political communities, creating new spaces for living together" (Bhattacharjee and Dev 2006, 2).

About the origin stories of some Australian aborigines groups, Christian says,

Told over many nights and days, their stories describe the big paradigm ideas of the Lake Mungo people.... As they talk about the stars, the landscape, the wombats and the wallabies, and the world of their ancestors, the teachers build a shared map of understanding that shows members of the community their place in a rich, beautiful, and sometimes terrifying universe: this is what you are; this is where you came from; this is who existed before you were born; this is the whole thing of which you are a small part; these are the responsibilities and challenges of living in a community of others like yourself. ... [Without them] people could fall into a sense of despair and meaninglessness (Christian 2018a, 7-8).

Big History would provide a source for ethnonarratives of a different kind, one that is built "... on the global traditions of modern science. ... [And] like the origin stories of Confucianism or early Buddhism, the modern story is about a universe that just is. Any sense of meaning comes not from the universe, but from us humans" (Christian 2018a, 9).

The social imaginary offers explanations of how 'we'-the members of the imagined community of mostly strangers-fit together, how things go on between us, the expectations we have of each other and outsiders, and the deeper normative notions and images that underlie those expectations (Patomäki and Steger 2010, 1057).

Moreover, in the light of the Anthropocene, the future would not entail different fates according to affiliation to sub-planetary collectives. We should expect stark geopolitical and social inequalities in the impacts of human-induced 
climate change, but, all in all, there is no escape for any human living on the planet, not to say any living creature in the biosphere. "The modern origin story tells of the heritage all humans share, and so it can prepare us for the huge challenges and opportunities that all of us face at this pivotal moment in the history of planet Earth" (Christian 2018a, 10).

The starting point of non-Eurocentric and planetary 'Big History' is that-as human capacities emerged from nature-human societies remain part of nature. . . . Big History narratives draw on a series of mutually strengthening prototypes, metaphors and framings that logically lead to envisioning the place of 'us' in the framework of 'global,' 'planetary' or even 'cosmic' time and space. It encourages new framings of human activities in terms of a new geological era, an anthropocene, as the most recent period in the Earth's history involving human activities that have a significant impact on the Earth's climate and ecosystems (Patomäki and Steger 2010, 1061).

So, the knowledge gained through Big History research can provide an origin story that raises public awareness about our future as a species and about the responsibilities that we must assume because of the destructive power-to the planet, to other species, to ourselves-that we achieved through our collective action. There should be no space for fairytale-like narratives, and the worst of humankind should be brought to the surface with the support of the most solid transdisciplinary knowledge available. Maybe we should consider Big History less around-thebonfire storytelling and more as an exercise in species-wide psychoanalysis.

As should be expected, not everyone is comfortable with the idea, and this fact will bring Michael Beard once more to the scene for a final act. The study of Big History can provide such a comprehensive narrative about the cosmos, life, and the unintended consequences of human societies that its likely outcome is leading to ethical reasoning among students and researchers. This is not guaranteed, of course, but the doors are open. Attaining a macro and micro-ethical stance through the acquiring of knowledge-natural sciences and the humanities as one-would certainly be considered a public good, a citizenship gold standard. Because of all of this, Christian says that Big History, with its pervasiveness, could be understood as a "modern creation myth" (Chris tian 2004, 1). This mention of a mythological condition refers to foundational aspects of the psyche and of human cognition inscribed in hundreds of thousands years of evolution (Stevens 1990). As Jung stated,

From the unconscious there emanate determining influences which, independently of tradition, guarantee in every single individual a similarity and even a sameness of experience, and also of the way it is represented imaginatively. One of the main proofs of this is the almost universal parallelism between mythological motifs, which, on account of their quality as primordial images, I have called archetypes. (Jung 1936/1968, CW 9 pt.1 §118).

Notwithstanding, Big History has been accused of "remythologizing" scientific facts (Hesketh 2014, 176), as though a mythical narrative structure were something inferior, savage, primitive, pagan, or an apostasy against the Modernity god. That is a trivial understanding and cannot be taken seriously. "The standard modern meaning of myth has been that of a narrative that has no basis in reason and cannot be true. Mythos is opposed to logos" (Patomäki 2019, 77), but, as Giambattista Vico asserts, "mythos and logos are mutually implicated." In this case, "If a myth is lived by people in their everyday practices and institutions, the resulting social order testifies to the truth of that myth. Hence, in order to know the human world, we must know its constitutive myths." Big History, as a creation myth in the Anthropocene, founded on fair and sound academic practices, is open to criticism and permanent revision and, therefore, is averse to dogmatism. In no way is this a necessary contradiction to the definition of myth; so "the stories we are telling, involving anticipations of possible futures, must be open to criticism and revisable in a systematic fashion" (Patomäki 2019, 78).

The kind of criticism presented by Hesketh is 
deeply instructive because it signals the epistemological expectations of most of disciplinarymodern-Eurocentric academic thought. Hesketh believes that "the notion of remythologizing science is an implicit rhetorical move of much popular science literature" (Hesketh 2014, 181), and that it should come with criticism. In fact, however, this is something that attests to the social responsibility of both genres in trying to make complex academic knowledge understandable to a wider audience.

There is something derogatory in Hesketh's allusion to popular science, as though wellaccomplished scientists like Lee Smolin, Stephen Hawking, Neil deGrasse Tyson and Sean Carroll woke up one day and decided that writing baloney and earning big money would compensate for tossing their professional reputations in the dustbin. Sound scientific ideas are offered both in Big History and in popular science books, and if they come in a format that widens the readership, some academicians, on the top of their ivory towers, may fail to notice.

This takes us back to Michael Beard. Perhaps intoxicated by success and western, modern epistemology, the Nobel laureate could not grasp at all the ethical and social responsibility entailed by knowledge, especially his own knowledge; Beard was entombed by anomie, and he had no tools to get out of it. Hesketh was troubled by the fact that Big History and popular science books "seek something closer to revelation than to enlightenment" (Hesketh 2014, 181). Well, like many real life academicians, we are pretty sure that our fictional laureate was well-served by Enlightenment thinking over the course of his life, but that deprived of the sense of awe, of the consciousness of being part of the cosmos, that is, of all existence, incapable of looking into the eyes of a fellow animal-whatever the species-and of seeing himself in it, he was thereby prevented from recognizing the dangers of the unintended consequences of his acts and omissions, unable to understand with his entire embodied cognition (not just with his solipsistic mind) that he is merely stardust: like everything else. What could Beard teach anyone that could affect genuinely their lives and the lives of the creatures around them?
How could his encyclopedic knowledge, his refined erudition, enhance his primate empathic powers so that he could become a valuable planetary citizen, to the benefit of others?

Maybe these questions could find some answers in the future, not only through research and theoretical work on Big History, but also through the praxis inspired by it. As we suggest here, there is little ground for claiming neither "neutrality" nor "distancing" when it refers to the ethical stance of a researcher toward the world around him or her. This is a matter of 'responseability', as Donna Haraway says. The path is not entirely clear, and, as Big History establishes itself as an academic endeavor, its practitioners must be aware of the perils of taking some things for granted.

As the little imp who haunted Socratesmaking him as controversial and iconoclastic as possible-there is also a Michael Beard lurking around the corner, but not to make big historians as inquisitive as they can be. Beard is there to lure big historians toward a false Apollonian nirvana made of law, order, straight lines, objectivity and unambiguity, represented by the idea of a "grand unifying theory of the past." When such a prospect is longed for, it makes it easier for one to pursue a detached way of being in the world right at this moment because, after all, the explanation for everything-and the cure for all evil—will be written in the same textbook. Every alternative path will end up absorbed-if they lead toward the light of consilience-or eliminated-if they insist on the darkness of particularity. There would be no alternative standpoint from where Big History could be evaluated. There will be no opportunity to learn from dissent. No auriga would whisper "Memento Mori" to Caesar's ears. In that case, why should we care about climate change, deforestation, animal exploitation, inequality, war, poverty, geopolitics-all of these small things happening under our noses-if "humankind" is racing toward a technoliberal Kurtzweilian turning point? Let's live our lives as usual, enjoy the pleasures of overconsumption, and indulge in apathy because our heroic task is to reveal the secrets of the cosmos someday. This should grant all the emotional and irrational 
demands for an ethical stance toward scientists like us.

As it comes to age, Big History needs critical theory. This is not a revolutionary plea. The biohumanities advance nowadays as an applied field of knowledge with four objectives: "deepening our understanding of biology itself, engaging in constructive science criticism, creating alternative visions of biology, and achieving critical science communication" (Stotz and Griffiths 2008, 44). Big History will fall victim to its own success if it does not accept dissent and epistemological criticism as part of its métier. David Blanks has an interesting analogy to this need for critical theory:

Imagine big history as a large house. There are rooms for physicists and geologists, chemists, biologists, social scientists, and yes, artists and musicians too. They live and work together and share a space which represents a grand narrative that combines areas of expertise. ... But hidden inside the walls and under the floorboards of that house are the electrical and plumbing systems upon which they depend. The inhabitants take these for granted and none has been trained as an electrician or a plumber-which is fine until the power goes out or the hot water stops working. When this happens they will need to call in a specialist, someone who understands a building's internal working. This is when they will need a theorist (Blanks 2019, 234).

If we just add to Blanks' observation that the relationship between any field of knowledge with critical theory must be more a matter of preventive maintenance than of fixing what is broken (when it happens), we strongly disapprove of Richard Feynman's impressions. As he supposedly said in one of his worst "Michael Beard moments," "the philosophy of science is about as useful to scientists as ornithology is to birds." This phrase has something of the apocryphal about it. It is regularly quoted, but its origins are a little controversial. We are not, however, interested in discussing Feynman's personality. What we want is to raise awareness of the dangers Big History faces, and to do that, we must realize that "philosophy and history of science may be as val- uable to science as conservation biology is to birds" (Stoltz and Griffiths 2008, 44).

Every kind of human knowledge needs to have its theories, methods, hypotheses and especially aprioris, scrutinized. They belong to the everyday of academic work and usually bring moral, ethical, aesthetical, epistemological and ideological content in a subliminal way. As these hidden assumptions are theoretical, they are previous to analytical work, and as such, they have the power to frame scientific conclusions. It may sound a little obvious, but scientific evidence-of any kind-will not speak for itself. All it can tell us depends on the questions we ask, and these questions are determined by our assumptions (Bloch 2001). "Meaning does not emerge from the empirical evidence all on its own. One cannot, as some big historians claim, remove oneself from the equation by taking academic distance from the subject. This is theoretically naïve" (Blanks 2019, 235).

Reclaiming the goal of achieving convergent modalities of knowledge must necessarily invoke plurality-we speak about forms, not $a$ form: infinite diversity, in infinite combinations. The disciplinary approach toward science is to consider the methods, techniques, concepts, theories and objects of a given discipline as a world in itself. All mediations with the outer world (other disciplines) must be regulated, sanitized, or run the risk of producing contamination. Big historians, in their desire to achieve a "grand unifying theory of the past," are perhaps looking for a strange way to "disciplinarize" Big History. The expectation of achieving this may carry between the lines a vision of integral knowledge as a no-boundary universe. As such, there is no North or South, in or out. In these terms, and supposing that such a unified theory is feasible, Big History could encapsulate its own philosophy of science. If so, who will watch the watchmen? We are not questioning here whether or not a theory of everything is more fantastic than the alchemical lapis philosophorum; we are questioning the ethics and values behind the search. As Michael Beard says, "Let the philosophers of science delude themselves to the contrary, physics was free of human taint, it described a world that would still exist if 
men and women and all their sorrows did not" (McEwan 2011, 11). He could also ask to all big historians: how distant from my world are you, consilience seekers? It is never enough to remember an old, worn epigram: "Whoever fights with monsters should see to it that he does not become one himself. And when you stare for a long time into an abyss, the abyss stares back into you" (Nietzsche [1886] 2002, 69).

\section{References}

Atwood, M. 2003. Oryx and Crake. New York: Anchor Books.

Bhattacharjee, S. and R. Dev. 2006. "Introduction." In Ethno-Narratives: Identity and Experience in North East India, edited by S. Bhattacharjee and R. Dev, 1-14. Delhi: Anshah.

Blanks, D. 2019. "Big History and Critical Theory: Science, History and Why Theory Matters." In The Routledge Companion to Big History, edited by C. Benjamin, E. Quaedackers, and D. Baker, 233-249. London: Routledge.

Bloch, M. 2001. Apologia da História ou o Ofício do Historiador. Rio de Janeiro: Jorge Zahar Editor.

Chakrabarty, D. 2009. "The Climate of History: Four Theses." Critical Inquiry 35 (2): 197-222. doi: 10.1086/596640.

Christian, D. 1991. "The Case for 'Big History'." Journal of World History 2 (2): 223-238.

---. 2004. Maps of Time: An Introduction to Big History. Berkeley: University of California Press.

---. 2018a. Origin Story: A Big History of Everything. London: Allen Lane.

---. 2018b. "What is Big History?" Journal of Big History 1 (1): 4-19. doi:10.22339/jbh.vii1.2241.

---. 2019. "The Keen Longing for Unified, Allembracing Knowledge': Big History, Cosmic Evolution, and New Research Agendas." Journal of Big History 3 (3): 3-18. doi:10.22339/ jbh.v3i3.332.

Comte, A. 1978. Catecismo Positivista (Positivist Catechism). São Paulo: Abril Cultural.

Diamandis, E. 2013. "Nobelitis: A Common Disease among Nobel Laureates?" Clinical Chemistry and Laboratory Medicine 51 (8): 1573
-1574. doi: 10.1515/cclm-20133-0273.

Ferreira, A. B. H. 1975. Novo Dicionário Aurélio. Rio de Janeiro: Nova Fronteira.

Foley, R. 2003. Os Humanos antes $d a$ Humanidade: Uma Perspectiva Evolucionista (Humans before Humanity: An Evolutionary Perspective). São Paulo: Universidade Estadual Paulista.

Ghosh, A. 2016. The Great Derangement: Climate Change and the Unthinkable. Chicago: University of Chicago Press.

Hache, E., and B. Latour. 2010. "Morality or Moralism?: An Exercise in Sensitization." Common Knowledge 16 (2): 311-330. doi: 10.1215/0961754X -2009-109.

Haldon, J., et al. 2018. "History Meets Palaeoscience: Consilience and Collaboration in Studying Past Societal Responses to Environmental Change." PNAS 115 (13): 3210-3218. doi: 10.1073/ pnas.1716912115.

Hamilton, C. 2017. Defiant Earth: The Fate of Humans in the Anthropocene. Sydney: Allen \& Unwin.

Hawking, S. 2001. The Universe in a Nutshell. London: Bantam Press.

---. 2015. Uma Breve História do Tempo (A Brief History of Time). Rio de Janeiro: Intrínseca.

Hesketh, I. 2014. "The Story of Big History." History of the Present 4 (2): 171-202. doi: 10.5406/ historypresent.4.2.0171.

Humboldt, A. 1864. Cosmos: A Sketch of a Physical Description of the Universe, Volume I. London: Henry G. Bohn.

Jung. C. G. 1968. "Concerning the Archetypes, with Special Reference to the Anima Concept. (R. F. C. Hull, Trans)". In The Collected Works of C. G. Jung (Vol. 9 pt. 1, 2nd. ed., 54-72). New York: Princeton University Press (Original work published 1936).

Katerberg, W. 2018. "Is Big History a Movement Culture?" Journal of Big History 2 (1): 63-72. doi: 10.22339/jbh.v2i1.2255.

Kellish. J. “No Laughable Thing under the Sun': Satire, Realism, and the Crisis of Climate Change in Ian McEwan's Solar." Aesthetics of the Anthropocene: Articulating Geo-Logics in the Epoch of the New Human. https:// sites.fhi.duke.edu/anthropocene/comedy-and- 
climate-crisis/.

Latour, B. 1993. We Have Never Been Modern.

Cambridge: Harvard University Press.

---. 2017. Facing Gaia: Eight Lectures on the New Climatic Regime. Cambridge: Polity.

Marx, K., and F. Engels. 1977. "O Dezoito Brumário de Luís Bonaparte (The Eighteenth Brumaire of Louis Bonaparte)." In Textos: volume III, 199-285. São Paulo: Alfa-Omega.

McEwan, I. 2005. "A Boot Room in the Frozen North". https://capefarewell.com/explore/215a-boot-room-in-the-frozen-north.html.

McEwan, I. 2011. Solar. London: Vintage Books. Megill, A. 2015. "Big History' Old and New: Presuppositions, Limits, Alternatives". Journal of Philosophy of History 9 (2): 306-326. doi: 10.1163/18722636-12341305.

Morton, T. 2013. Hyperobjects: Philosophy and Ecology after the End of the World. Minneapolis: University of Minnesota Press.

Nietzsche, F. [1886] 2002. Beyond Good and Evil: Prelude to a Philosophy of the Future. Cambridge: Cambridge University Press.

Patomäki, H. 2019. "Mythopoetic Imagination as a Source of Critique and Reconstruction: Alternative Storylines about Our Place in Cosmos." Journal of Big History 3 (4): 77-97. doi: 10.22339/jbh.v3i4.3433.

Patomäki, H., and M. Steger. 2010. "Social Imaginaries and Big History: Towards a New Planetary Consciousness?" Futures (42) 10: 10561063. doi: 10.1016/j.futures.2010.08.004.

Rostow, W. 1971. Etapas do Desenvolvimento Econômico (The Stages of Economic Growth). Rio de Janeiro: Zahar.

Smolin, L. 1977. The Life of the Cosmos. New York: Oxford University Press.

Snow, C. P. 1961. The Two Cultures and the Scientific Revolution. New York: Cambridge University Press.

Snyder, L. 2019. "William Whewell". In The Stanford Encyclopedia of Philosophy, edited by E. Zalta. https://plato.stanford.edu/archives/ spr2019/entries/whewell/.

Stevens, A. 1990. Archetype: A Natural History of the Self. London: Routledge.

Stotz, K., and P. Griffiths. 2008. "Biohumanities: Rethinking the Relationship Between Biosci- ences, Philosophy and History of Science, and Society." The Quarterly Review of Biology (83) 1: 37-45.

Susskind, L. 2006. The Cosmic Landscape: String Theory and the Illusion of Intelligent Design. New York: Hachette Books. Kindle Edition.

Tamm, M. 2018. "Introduction". In Debating New Approaches in History, edited by P. Burke and M. Tamm. 1-20. London: Bloomsbury.

Tate. A. 2017. "The Storm-Cloud of the TwentyFirst Century: Biblical Apocalypse, Climate Change and Ian McEwan's Solar." The Glass 29: 3-12.

Trexler, A. 2015. Anthropocene Fictions: The Novel in a Time of Climate Change. Charlottesville: University of Virginia Press.

Wilson, E. 1998. Consilience: The Unity of Knowledge. New York: Vintage.

---. 2018. O Sentido da Existência Humana (The Meaning of Human Existence). São Paulo: Companhia das Letras.

\section{Endnotes}

${ }^{1}$ Notice the inversion here: it is not culture that is free from the taint of nature, as modern thought understands it, but the opposite: according to Beard, it is nature that is free from human taint, as though immune to human actions.

"“The boot room" episode and McEwan's experience on Cape Farewell's expedition were presented in McEwan 2005.

${ }^{3}$ Marxism recognizes that human agency is dialectically linked with long-term phenomena, which means that the synthesis of the interaction between contingency and structure imposes restrictions to the "human" side, at least. As the well-known passage says,

4"[Humans] make their own history, but they do not make it as they please; they do not make it under self-selected circumstances, but under circumstances existing already, given and transmitted from the past" (Marx 1977, 203). 